\title{
Cocaine Alters Cerebral Metabolism within the Ventral Striatum and Limbic Cortex of Monkeys
}

\author{
David Lyons, David P. Friedman, Michael A. Nader, and Linda J. Porrino \\ Center for the Neurobiological Investigation of Drugs of Abuse, Department of Physiology and Pharmacology, Bowman \\ Gray School of Medicine, Wake Forest University, Winston-Salem, North Carolina 27157
}

The functional consequences of acute cocaine administration in nonhuman primates were assessed using the quantitative $2-\left[{ }^{14} \mathrm{C}\right]$ deoxyglucose method. Local rates of cerebral metabolism were determined after an intravenous infusion of $1.0 \mathrm{mg} / \mathrm{kg}$ cocaine or vehicle in six awake cynomolgus monkeys (Macaca fascicularis) trained to sit calmly in a primate chair. Cocaine administration decreased glucose utilization in a discrete set of structures that included both cortical and subcortical portions of the limbic system. Glucose metabolism in the core and shell of the nucleus accumbens was decreased markedly, and smaller decrements were observed in the caudate and anterior putamen. In addition, cocaine administration produced significant decreases in limbic cortex. Metabolism was decreased in orbitofrontal cortex (areas 11, 12o, 13, 13a, 13b), portions of the gyrus rectus including area 25 , entorhinal cortex, and parts of the hippocampal formation. The cortical regions in which functional activity was altered provide dense projections to the nucleus accumbens, and the decreased activity in these projections may be responsible in part for the large alterations in functional activity within the ventral striatum. Decreased metabolism also was evident in the anterior nuclear group of the thalamus, raphe nuclei, and locus ceruleus. The acute cerebral metabolic effects of cocaine in the conscious macaque, therefore, were contained primarily within a set of interconnected limbic regions, including ventral prefrontal cortex, medial temporal regions, the ventral striatal complex, and anterior thalamus. The decreased rates of glucose metabolism reported here resemble decrements found using positron emission tomography in humans. In the rat, by contrast, metabolic activity increased and changes were focused in subcortical regions. The present results represent an important expansion of the neural circuitry on which cocaine acts in the monkey as compared with the rat, and this in turn implies that cocaine affects a broader spectra of behaviors in primates than in rodents.

Key words: monkey; cerebral metabolism; cocaine; limbic system; ventral striatum; nucleus accumbens; orbital and medial prefrontal cortex
Much of our understanding of the neurobiological basis of cocaine abuse is based on investigations performed in rodents. Rodent models of cocaine use have provided the means to explore the basic mechanisms of cocaine action on both a cellular and a molecular level (Koob and Bloom, 1988; Kalivas et al., 1993; Nestler et al., 1993) and have contributed significant insights into the role of the dopaminergic mesolimbic system in the activating and reinforcing effects of cocaine (Wise, 1978; Koob and Goeders, 1989; Kuhar et al., 1991). Rodent models, however, have important limitations, particularly with respect to questions regarding the neuroanatomical components involved in the response to cocaine. The added complexity of the topographical organization of the ventral striatum and its connections with surrounding brain regions in primates (Lynd-Balta and Haber, 1994a,b; Haber et al., 1995), especially when cortical connections are considered, can make extrapolations from rodent models to primates, including humans, problematic.

The development of in vivo neuroimaging techniques, including positron emission tomography (PET), single-photon emissioncomputed tomography (SPECT), and magnetic resonance imag-

Received Sept. 11, 1995; revised Nov. 1, 1995; accepted Nov. 6, 1995.

This research was supported by National Institute on Drug Abuse Grants DA09085 (L.J.P.), DA07955 (D.P.F.), and DA06829 (M.A.N.). We thank Dr. Kathleen Grant and Clittord Hubbard for their assistance in conducting these studies.

Correspondence should be addressed to Dr. Linda J. Porrino, Department of

Physiology and Pharmacology, Bowman Gray School of Medicine, Medical Center Boulevard, Winston-Salem, NC 27157-1083.

Copyright (C) 1996 Society for Neuroscience $0270-6474 / 96 / 161230-09 \$ 05.00 / 0$ ing, has made it possible to address some of these questions directly in conscious human drug abusers. A majority of these studies have investigated the withdrawal period during which cocaine is no longer in the bloodstream, concentrating on the long-term consequences of chronic cocaine abuse. Such studies have demonstrated, for example, that functional activation, as measured by changes in cerebral metabolism, increases significantly in cortical regions during the first week of abstinence from cocaine, but then falls below normal levels and remains depressed for at least 3 months (Volkow et al., 1991, 1992, 1993). Less clear, however, is the nature of the functional response to an acute exposure to cocaine in either drug-naive subjects or experienced drug users. Few studies have addressed this issue, primarily because of the difficulties inherent in administering abused substances to humans. In one study in which SPECT imaging of blood flow was used, Pearlson et al. (1993) showed that the acute administration of cocaine reduces blood flow in ventral frontal cortical regions and in basal ganglia. Decreases also have been found in global rates of cerebral metabolism after the administration of intravenous cocaine to a group of experienced polydrug abusers (London et al., 1990). Unfortunately, the interpretation of studies such as these in human cocaine abusers may be confounded by variable and incomplete drug histories, questionable nutritional status, comorbid psychiatric disorders, and the lack of control over psychological variables. Only with reservations, therefore, can these functional changes be attributed directly to cocaine in a population of chronic abusers. 
The purpose of the present study was to pursue questions raised by human studies with a nonhuman primate model in which carefully controlled experiments can be conducted without the confounds inherent in human research and with the spatial resolution of autoradiography. The goal was to identify the neuroanatomical substrates of the effects of the administration of a single acute dose of cocaine to cynomolgus monkeys, using the quantitative autoradiographic $2-\left[{ }^{14} \mathrm{C}\right]$ deoxyglucose $\left(2-\left[{ }^{14} \mathrm{C}\right] \mathrm{DG}\right)$ method (Sokoloff et al., 1977) as adapted for use in nonhuman primates (Kennedy et al., 1978). Because findings in rodents appear to be at odds with those reported in humans (London et al., 1990), a further purpose of this investigation was to compare the cerebral metabolic effects after acute cocaine administration in nonhuman primates with those reported in rodents (London et al., 1986; Porrino et al., 1988; Sharkey et al., 1991; Porrino, 1993) and humans (London et al., 1990; Pearlson et al., 1993).

\section{MATERIALS AND METHODS}

Animals and training. Six male cynomolgus monkeys (Macaca fascicularis) weighing $5.0-5.9 \mathrm{~kg}$ were housed under a $12 \mathrm{hr}$ light/dark cycle with access to food (Purina monkey chow) twice daily and water available ad libitum. At the start of the study, all monkeys were naive to cocaine and other psychostimulants. In addition, although previous medication included single doses of clonidine and/or haloperidol, all animals were cirug-free for at least 4 months before study, with the exception of ketamine, which was administered approximately once monthly to perform regular veterinary care. All procedures were performed in accordance with established practices as described in the National Institutes of Health guide for care and use of laboratory animals. In addition, all procedures were reviewed and approved by the Animal Care and Use Committee of Wake Forest University.

Monkeys were trained in daily $1 \mathrm{hr}$ sessions to sit partially restrained in a primate chair (Plastic I ahs, I ansing, MI), flanks supported, and with neck and feet loosely secured. Monkeys were free to move head, hands, and arms at all times. Training sessions continued for $\sim 2-3$ weeks until signs of distress were minimal. $\Lambda t$ this point, all animals sat comfortably in the primate chairs without struggling and accepted fruit, juice, and other treats readily from the investigators. Monkeys were randomly assigned to one of two groups: cocaine ( $1.0 \mathrm{mg} / \mathrm{kg}$, i.v.; $n=3)$, or saline vehicle $(0.1 \mathrm{ml} / \mathrm{kg}$, i.v.; $n=3)$.

Drug administration. Cocaine hydrochloride was obtained from the National Institute on Drug Abuse (Research Triangle Park, NC) and dissolved in physiological saline $(0.1 \mathrm{ml} / \mathrm{kg})$ immediately before administration. Equivalent volumes of saline were administered to control monkeys. Cocaine $(1.0 \mathrm{mg} / \mathrm{kg})$ or saline vehicle $(0.1 \mathrm{ml} / \mathrm{kg})$ was administered intravenously via the femoral catheter. This dose was the average cumulative intake of monkeys that maintains peak rates of responding during self-administration sessions in our laboratory (Nader and Reboussin, 1994). The $2-\left[{ }^{14} \mathrm{C}\right] \mathrm{DG}$ procedure was initiated 2 min after drug injection. Although the $2-\left[{ }^{14} \mathrm{C}\right] \mathrm{DG}$ method requires a total experimental period of $45 \mathrm{~min}$ to allow for clearance of unmetabolized tracer, the uptake and phosphorylation of $2-\left[{ }^{14} \mathrm{C}\right] \mathrm{DG}$ in brain reflect its metabolism predominantly in the first $5-10 \mathrm{~min}$ after its administration. The reason for this is that the tissue concentration of free $2-\left[{ }^{14} \mathrm{C}\right] \mathrm{DG}$ is highest during the first $5 \mathrm{~min}$ after injection (Sokoloff et al., 1977). The time of drug administration and the initiation of the $2-\left[{ }^{14} \mathrm{C}\right] \mathrm{DG}$ procedure, therefore, were chosen to ensure that maximum incorporation of tracer occurred during the time of peak effects of cocaine.

Measurement of local cerebral glucose utilization. A minimum of $1 \mathrm{~d}$ before the measurement of rates of local cerebral glucose metabolism with the $2-\left[{ }^{14} \mathrm{C}\right] \mathrm{DG}$ method, monkeys were anesthetized briefly with a mixture of ketamine $(15 \mathrm{mg} / \mathrm{kg}, \mathrm{i} . \mathrm{m}$.) and butorphanol $(0.18 \mathrm{mg} / \mathrm{kg}, \mathrm{i.m}$.). Polyethylene catheters were inserted into a femoral artery and vein to permit subsequent intravenous administration of cocaine, vehicle, and $2-\left[{ }^{14} \mathrm{C}\right] \mathrm{DG}$ and sampling of arterial blood during the course of the experimental procedure. The catheters then were arranged subcutaneously, and the monkeys were allowed to recover for a minimum of $24 \mathrm{hr}$.

On the experimental day, each monkey was seated in a primate chair in the testing facility in a manner identical to that used during training. The catheters were exposed, and the monkeys were permitted to sit quietly for $\sim 30 \mathrm{~min}$ before drug treatment. During this time, monkeys were offered small amounts of water or fruit juice. Monkeys exhibited no signs of discomfort.

Cocaine hydrochloride $(1.0 \mathrm{mg} / \mathrm{kg})$ or saline vehicle $(0.1 \mathrm{ml} / \mathrm{kg})$ was infused intravenously over a $15 \mathrm{sec}$ interval. Two minutes after this injection, the experimental procedure was initiated by the injection of an intravenous pulse of $100 \mu \mathrm{Ci} / \mathrm{kg} 2$-deoxy-D-[1- $\left.{ }^{14} \mathrm{C}\right]$ glucose (DuPont NEN, Boston, MA; specific activity $50-55 \mathrm{mCi} / \mathrm{mmol}$ ) followed by a flush of heparinized saline. Timed arterial blood samples were drawn thereafter at a schedule sufficient to define the time course of the arterial $2-\left[{ }^{14} \mathrm{C}\right] \mathrm{DG}$ and glucose concentrations. Arterial blood samples were centrifuged immediately. Plasma concentrations of $2-\left[{ }^{14} \mathrm{C}\right] \mathrm{DG}$ were determined by liquid scintillation spectrophotometry (Beckman Instruments, Fullerton, CA), and plasma glucose concentrations were assessed with a glucose analyzer (Beckman). Approximately $45 \mathrm{~min}$ after tracer injection, the animals were killed by an intravenous overdose of sodium pentobarbital $(100 \mathrm{mg} / \mathrm{kg})$. Brains were removed rapidly, blocked in three parts, frozen in isopentane $\left(-45^{\circ} \mathrm{C}\right)$, and stored at $-70^{\circ} \mathrm{C}$ until processing for autoradiography. Coronal sections $(20 \mu \mathrm{m}$ thick) were cut in a cryostat maintained at $-22^{\circ} \mathrm{C}$. Four of every ten sections were thaw-mounted on glass coverslips, dried on a hot plate, and autoradiographed with Kodak EMC $\mathrm{x}$-ray film (Rochester, NY) for $15 \mathrm{~d}$, along with a set of $\left[{ }^{14} \mathrm{C}\right]$ nuethylmethacrylate standards (Amersham, Arlington Heights, IL) previously calibrated for their equivalent ${ }^{14} \mathrm{C}$ concentrations in $20 \mu \mathrm{m}$ brain sections. Autoradiograms were developed by hand in Kodak GBX developer, indicator stop bath, and rapid fix at $68^{\circ} \mathrm{C}$.

Autoradiograms were analyzed by quantitative densitometry with a computer-assisted image-processing system (Imaging Research, St. Catharine's, Ontario, Canada). Optical density measurements for each structure were made in a minimum of eight brain sections. Tissue ${ }^{14} \mathrm{C}$ concentrations were determined from the optical densities and a calibration curve obtained by densitometric analysis of the autoradiograms of the calibrated standards. Glucose utilization then was calculated from the local-tissue ${ }^{14} \mathrm{C}$ concentrations, the time course of the plasma $2-\left[{ }^{14} \mathrm{C}\right] \mathrm{DG}$ and glucose concentrations, and the appropriate kinetic constants (Kennedy et al., 1978) by the operational equation of the method (Sokoloff et al., 1977).

Statistical analysis. Rates of glucose utilization were measured in 67 distinct brain regions. Global rates of cerebral metabolism were estimated as the mean (weighted by region size) of all measured cerebral regions. Statistical analysis was performed on values of rates of local cerebral glucose utilization obtained for each individual cerebral structure by means of a Student's $t$ test for independent samples. Comparisons were made between values of rates of glucose utilization in control or saline-treated animals and monkeys receiving cocaine.

\section{RESULTS}

\section{Behavioral observations}

The acute administration of a moderate dose of cocaine to monkeys produced mild behavioral activation. Monkeys displayed "lip smacking," head turning, and some small increases in upper limb movement. No changes in lower limb movement were noted. Although activation began immediately after cocaine infusion and persisted for $\sim 10 \mathrm{~min}$, the degree of movement was in essence relatively small. Monkeys remained quiet and alert for the remainder of the experimental period. Vehicle-treated monkeys sat quietly during the entire $2-\left[{ }^{14} \mathrm{C}\right] \mathrm{DG}$ procedure and displayed none of the behavioral characteristics observed after cocaine infusions.

\section{Rates of local cerebral glucose utilization}

Rates of local cerebral glucose utilization for the 67 brain regions examined are shown in Tables 1-3. Global rates of cerebral metabolism in the cocaine- and vehicle-treated groups did not differ from one another significantly (saline, $41.5 \pm 1$; cocaine, $36.1 \pm 1$ ). Significant changes in rates of local cerebral glucose utilization were observed in 21 regions $(p<0.05)$, all of which displayed decreases in cerebral metabolic rates after the administration of cocaine $(1.0 \mathrm{mg} / \mathrm{kg})$. 
Table 1. Local cerebral metabolic rates $\left(\mu \mathrm{mol} \cdot 100 \mathrm{gm}^{-1} \cdot \mathrm{min}^{-1}\right)$ for glucose in subcortical limbic regions of cynomolgus monkeys after i.v. saline or $1.0 \mathrm{mg} / \mathrm{kg}$ i.v. cocaine

\begin{tabular}{llll} 
& $\begin{array}{l}\text { Saline } \\
\text { Mean } \pm \text { SEM } \\
(n=3)\end{array}$ & $\begin{array}{l}\text { Cocaine } \\
\text { Mean } \pm \text { SEM } \\
(n=3)\end{array}$ & $\begin{array}{l}\text { Percentage } \\
\text { change }\end{array}$ \\
\hline $\begin{array}{l}\text { Mesolimbic system and } \\
\text { related structures }\end{array}$ & & & \\
$\quad$ Medial accumbens (shell) & $39 \pm 2$ & $28 \pm 1^{*}$ & -28 \\
Lateral accumbens (core) & $41 \pm 2$ & $29 \pm 1^{*}$ & -29 \\
Olfactory tubercle & $38 \pm 3$ & $29 \pm 2$ & -23 \\
Ventral pallidum & $28 \pm 3$ & $27 \pm 1$ & -4 \\
Bed nucleus stria & & & \\
$\quad$ terminalis & $25 \pm 2$ & $23 \pm 1$ & -8 \\
Lateral hypothalamus & $31 \pm 2$ & $29 \pm 2$ & -10 \\
Ventral tegmental area & $27 \pm 2$ & $30 \pm 3$ & -15 \\
$\quad$ Mammillary bodies & $65 \pm 3$ & $55 \pm 4$ & -15 \\
Hippocampal formation & & & \\
Hippocampus, CA1 & $30 \pm 1$ & $26 \pm 1^{*}$ & -13 \\
Hippocampus, CA3 & $30 \pm 1$ & $27 \pm 1$ & -10 \\
Dentate gyrus & $33 \pm 2$ & $28 \pm 1$ & -15 \\
Subicular complex & $38 \pm 1$ & $30 \pm 1^{*}$ & -21 \\
Amygdala & & & \\
Central nucleus & $23 \pm 3$ & $22 \pm 1$ & -4 \\
Medial nucleus & $26 \pm 4$ & $29 \pm 2$ & 12 \\
Accessory nucleus & $28 \pm 2$ & $27 \pm 2$ & -4 \\
Mediobasal nucleus & $29 \pm 2$ & $25 \pm 2$ & -14 \\
Basolateral nucleus & $36 \pm 3$ & $35 \pm 2$ & -3 \\
\hline
\end{tabular}

${ }^{*}$ Indicates a significant difference from saline (Student's $t$ test, $p<0.05$ ).

\section{Mesolimbic system and related structures}

Acute cocaine administration significantly reduced glucose utilization in both subdivisions of the nucleus accumbens (core, $-29 \%$; shell, $-28 \%$ ) (Table 1, Fig. 1). These changes were among the largest noted in any brain region. In contrast, cocaine treatment did not alter glucose utilization in the lateral septum, bed nucleus of the stria terminalis, or any portion of the amygdala (Table 1). The latter subcortical limbic areas similar to the ventral striatum receive dopaminergic inputs from the ventral midbrain but showed no metabolic response to cocaine.

\section{Basal ganglia and related structures}

Changes in glucose utilization were restricted to highly discrete portions of the nigrostriatal system and related basal ganglia structures (Table 2). Acute cocaine administration significantly decreased cerebral metabolism in the dorsal extent of the anterior caudate nucleus $(-18 \%)$ and the anterior portions of the putamen $(-22 \%)$. Reduced rates of glucose utilization also were observed in the subthalamic nucleus $(-20 \%)$. Significant changes were not observed in any other portion of this system.

\section{Cerebral cortex}

The most striking response to acute cocaine administration in monkeys occurred in limbic prefrontal cortex, particularly within portions of orbitofrontal cortex and along the medial wall of the frontal lobe (Table 3). To establish the exact topography of the response to cocaine in these areas, prefrontal cortex was further subdivided according to the boundaries determined by Ray and Price (1993). Figure 2 shows the response to cocaine on a flattened map of the prefrontal cortex in the monkey. Cocaine had its most intense effects in areas $11(-24 \%), 120(-25 \%), 13$
Table 2. Local cerebral metabolic rates $\left(\mu \mathrm{mol} \cdot 100 \mathrm{gm}^{-1} \cdot \mathrm{min}^{-1}\right)$ for glucose in basal ganglia, thalamus, brainstem, cerebellum, and white matter of cynomolgus monkeys after i.v. saline or $1.0 \mathrm{mg} / \mathrm{kg}$ i.v. cocaine

\begin{tabular}{|c|c|c|c|}
\hline & $\begin{array}{l}\text { Saline } \\
\text { Mean } \pm \text { SEM } \\
(n=3)\end{array}$ & $\begin{array}{l}\text { Cocaine } \\
\text { Mean } \pm \text { SEM } \\
(n=3)\end{array}$ & $\begin{array}{l}\text { Percentage } \\
\text { change }\end{array}$ \\
\hline \multicolumn{4}{|l|}{$\begin{array}{l}\text { Basal ganglia and related } \\
\text { structures }\end{array}$} \\
\hline Dorsal caudate & $54 \pm 3$ & $44 \pm 2^{*}$ & -18 \\
\hline Anterior putamen & $51 \pm 3$ & $40 \pm 1^{*}$ & -22 \\
\hline Posterior putamen & $52 \pm 4$ & $45 \pm 1$ & -13 \\
\hline Globus pallidus, external & $31 \pm 2$ & $30 \pm 1$ & -3 \\
\hline Globus pallidus, internal & $33 \pm 1$ & $32 \pm 3$ & -3 \\
\hline Subthalamus & $61 \pm 2$ & $49 \pm 3^{*}$ & -20 \\
\hline Red nucleus & $46 \pm 2$ & $40 \pm 2$ & -13 \\
\hline $\begin{array}{l}\text { Substantia nigra, } \\
\text { compacta }\end{array}$ & $41 \pm 1$ & $39 \pm 3$ & -5 \\
\hline $\begin{array}{l}\text { Substantia nigra, } \\
\text { reticulata }\end{array}$ & $35 \pm 1$ & $37 \pm 2$ & 6 \\
\hline \multicolumn{4}{|l|}{ Thalamus } \\
\hline $\begin{array}{l}\text { Anteroventral/antero- } \\
\text { medial }\end{array}$ & $61 \pm 1$ & $53 \pm 2^{*}$ & -13 \\
\hline Ventroanterior & $43 \pm 1$ & $35 \pm 3^{*}$ & -19 \\
\hline Paraventricular & $38 \pm 3$ & $32 \pm 4^{*}$ & -16 \\
\hline Reuniens & $36 \pm 3$ & $35 \pm 3$ & -3 \\
\hline $\begin{array}{l}\text { Mediodorsal, magno- } \\
\text { cellular }\end{array}$ & $54 \pm 1$ & $52 \pm 5$ & -4 \\
\hline Mediodorsal, parvi & & & \\
\hline cellular & $57 \pm 2$ & $54 \pm 3$ & -5 \\
\hline Ventrolateral & $43 \pm 3$ & $35 \pm 2$ & -19 \\
\hline Medial habenula & $39 \pm 3$ & $32 \pm 1$ & -18 \\
\hline Lateral habenula & $41 \pm 2$ & $29 \pm 1^{*}$ & -29 \\
\hline \multicolumn{4}{|l|}{ Brain stem and cerebellum } \\
\hline Dorsal raphe & $38 \pm 1$ & $32 \pm 1^{*}$ & -16 \\
\hline Medial raphe & $34 \perp 1$ & $28 \pm 1^{*}$ & -18 \\
\hline Locus ceruleus & $38 \pm 2$ & $30 \pm 1^{*}$ & -21 \\
\hline Cerehellar cortex & $36+1$ & $42+2$ & 17 \\
\hline \multicolumn{4}{|l|}{ White matter } \\
\hline Anterior commissure & $16 \pm 3$ & $12 \pm 1$ & -25 \\
\hline Corpus callosum & $17 \pm 2$ & $13 \pm 1$ & -24 \\
\hline Internal capsule & $20 \pm 3$ & $17 \pm 2$ & -15 \\
\hline
\end{tabular}

*Indicates a significant difference from saline (Student's $t$ test, $p<0.05$ ).

$(-24 \%), 13 \mathrm{a}(-35 \%), 13 \mathrm{~b}(-29 \%)$, and $25(-34 \%)$. The effect was less intense lateral to areas 13 and 120 and disappeared completely in the lateral prefrontal cortex.

The effects of the acute administration of cocaine in limbic cortex were in marked contrast to those in other neocortical areas. Acute cocaine did not alter rates of glucose utilization in any measured sensory, motor, or association region, including area 46 in the banks of the principal sulcus, area 12 on the inferior prefrontal convexity, the forelimb region of area 4 on the anterior bank of the central sulcus and the same representation in area $3 \mathrm{~b}$ on the posterior bank of the central sulcus, the lateral portion of striate cortex, and V2 immediately adjacent to it (Table 3). The effects of cocaine administration, therefore, were clearly localized to anterior limbic cortical areas.

The acute administration of cocaine also decreased rates of local cerebral glucose utilization within the hippocampal complex (Table 1, Fig. 1). Metabolism decreased in the CA1 subfield of 

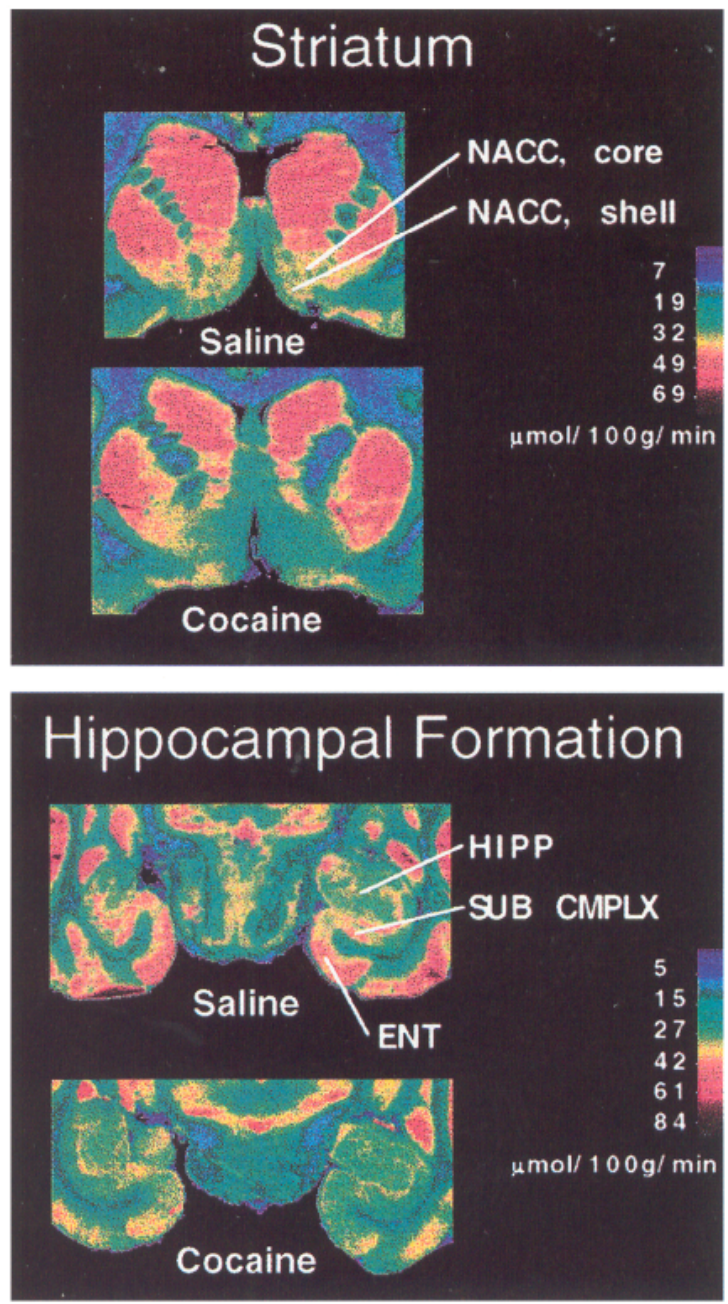

Figure 1. Effects of the acute intravenous administration of cocaine (1.0 $\mathrm{mg} / \mathrm{kg})$ and saline $(0.1 \mathrm{ml} / \mathrm{kg})$ on rates of local cerebral glucose utilization in the ventral striatum (top panel) and in the hippocampal formation (bottom panel). Shown are color-coded transformations of autoradiograms of coronal sections of cynomolgus monkey brain at the level of the ventral striatum (top panel) and the hippocampus (bottom panel) in which each color represents a range of rates of glucose utilization $(\mu \mathrm{mol} \cdot 100$ $\mathrm{gm}^{-1} \cdot \mathrm{min}^{-1}$ ) calculated from calibrated standards exposed along with the brain sections. Autoradiograms were normalized to saline controls. Note in the top panel the significant reduction in rates of glucose utilization in each of the subdivisions of the nucleus accumbens in the cocaine-treated monkeys. In the bottom panel note the significant reduction in rates of glucose utilization within portions of the hippocampus and the entorhinal cortex in the cocaine-treated monkeys. ENT, Entorhinal cortex; HIPP, hippocampus; $N A C C$, nucleus accumbens; SUB CMPLX, subicular complex.

hippocampus $(-13 \%)$, subicular complex $(-21 \%)$, and entorhinal cortex $(-21 \%)$ (Table 3$)$.

No changes in cerebral metabolism were noted in the regions of the primary somatosensory and motor areas of cortex in which the hand and face are represented. This lack of changes reflects the small degree of movement elicited by cocaine administration (Table 3).

\section{Thalamus}

Acute cocaine administration had few significant effects on rates of glucose utilization in the thalamus (Table 2). Reduced glucose metabolism was evident only in the ventral and medial nuclei of the anterior group $(-13 \%)$, the paraventricular nucleus $(-16 \%)$, and the ventral anterior nucleus $(-19 \%)$. Despite the widespread changes in the orbitofrontal cortex, there was only a trend toward reduced glucose metabolism in any portion of the mediodorsal nucleus of the thalamus.
Figure 2. Distribution of changes in rates of local cerebral glucose metabolism in prefrontal cortex. Four coronal sections adapted from the atlas of Szabo and Cowan (1984) are shown on the left. A representative unfolded two-dimensional map of the prefrontal cortex of cynomolgus monkey adapted from Ray and Price (1993) appears on the right. The color coding indicates differing degrees of decreases in glucose utilization in prefrontal areas caused by cocaine administration. Red, $>20 \%$ decreases; yellow, $>15 \%$ decreases; blue, $>10 \%$ decreases.
$+38$

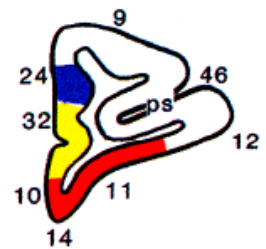

$+35$

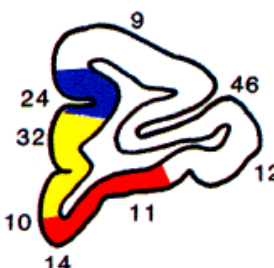

$+32$

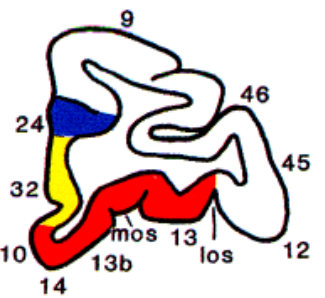

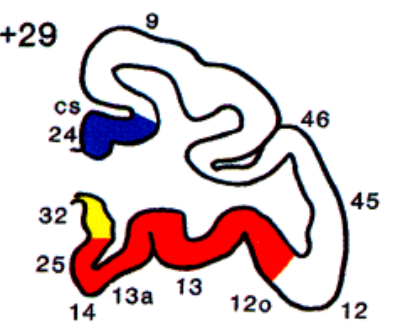

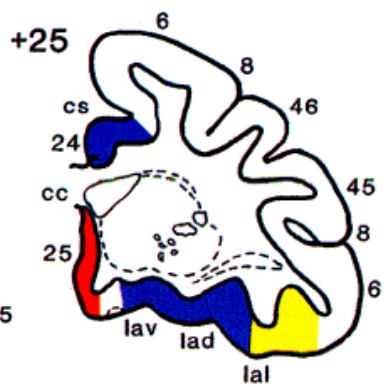

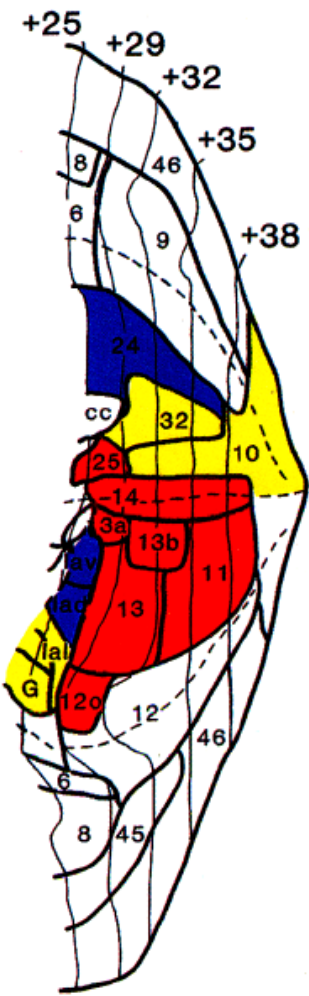


Table 3. Local cerebral metabolic rates $\left(\mu \mathrm{mol} \cdot 100 \mathrm{gm}^{-1} \cdot \mathrm{min}^{-1}\right)$ for glucose in cortex of cynomolgus monkeys after i.v, saline or $1.0 \mathrm{mg} / \mathrm{kg}$ i.v. cocaine

\begin{tabular}{|c|c|c|c|}
\hline & $\begin{array}{l}\text { Saline } \\
\text { Mean } \pm \text { SEM } \\
(n=3)\end{array}$ & $\begin{array}{l}\text { Cocaine } \\
\text { Mean } \pm \text { SEM } \\
(n=3)\end{array}$ & $\begin{array}{l}\text { Percentage } \\
\text { change }\end{array}$ \\
\hline \multicolumn{4}{|l|}{ Neocortex } \\
\hline Frontal pole (area 10) & $46 \pm 2$ & $39 \pm 3$ & -15 \\
\hline Principal sulcus (area 46) & $53 \pm 3$ & $49 \pm 2$ & -8 \\
\hline $\begin{array}{l}\text { Inferior prefrontal } \\
\text { convexity (area } 12)\end{array}$ & $46 \pm 1$ & $47 \pm 4$ & 2 \\
\hline Motor cortex (area 4) & $52 \pm 4$ & $48 \pm 1$ & -8 \\
\hline $\begin{array}{l}\text { Somatosensory cortex } \\
\text { (area 3) }\end{array}$ & $60 \pm 1$ & $59 \pm 1$ & -2 \\
\hline $\begin{array}{l}\text { Prestriate cortex } \\
\quad(\text { area 18) }\end{array}$ & $58 \pm 3$ & $56 \pm 2$ & -3 \\
\hline \multicolumn{4}{|l|}{ Limbic cortex } \\
\hline Gyrus rectus (area 14) & $42 \pm 2$ & $33 \pm 4$ & -21 \\
\hline $\begin{array}{l}\text { Entorhinal cortex } \\
\quad \text { (area 28) }\end{array}$ & $39 \pm 2$ & $31 \pm 1^{*}$ & -21 \\
\hline $\begin{array}{l}\text { Perirhinal cortex } \\
\quad(\text { area } 20)\end{array}$ & $36 \pm 2$ & $31 \pm 2$ & -14 \\
\hline $\begin{array}{l}\text { Prepiriform olfactory } \\
\text { cortex }\end{array}$ & $44 \pm 3$ & $38 \pm 2$ & -14 \\
\hline \multicolumn{4}{|l|}{ Orbital cortex } \\
\hline Area 11 & $51 \pm 3$ & $39 \pm 1^{*}$ & -24 \\
\hline Area 13a & $46 \pm 2$ & $30 \pm 1^{*}$ & -35 \\
\hline Area $13 b$ & $48 \pm 1$ & $34 \pm 1^{*}$ & -29 \\
\hline Area 13 & $50 \pm 1$ & $38 \pm 2^{*}$ & -24 \\
\hline Area 120 & $52 \pm 1$ & $39 \pm 2^{*}$ & -25 \\
\hline \multicolumn{4}{|l|}{ Cingulate } \\
\hline Area 23 & $46 \pm 3$ & $37 \pm 3$ & -20 \\
\hline Area 24 & $43 \pm 2$ & $38 \pm 3$ & -12 \\
\hline Area 24 & $48 \pm 2$ & $42 \pm 2$ & -12 \\
\hline Area 25 & $44 \pm 3$ & $29 \pm 3 *$ & -34 \\
\hline Area 32 & $42 \pm 1$ & $34 \pm 4$ & -19 \\
\hline \multicolumn{4}{|l|}{ Anteroventral insula } \\
\hline $\mathrm{Iapm} / \mathrm{Iai}$ & $33 \pm 3$ & $30 \pm 3$ & -9 \\
\hline la1 & $38 \pm 3$ & $30 \pm 3$ & -21 \\
\hline G & $44 \pm 4$ & $35 \pm 4$ & -20 \\
\hline \multicolumn{4}{|l|}{ Temporal pole } \\
\hline Medial & $37 \pm 2$ & $32 \pm 3$ & -14 \\
\hline Lateral & $39 \pm 2$ & $32 \pm 3$ & -18 \\
\hline
\end{tabular}

"Indicates a significant difference from saline (Student's $t$ test, $p<0.05$ ).

\section{Brainstem regions}

Brainstcm structures comprising monoamine-containing neuronal cell bodies were examined in the present investigation (Table 2). Acute cocaine administration significantly reduced glucose utilization in the dorsal $(-15 \%)$ and median $(-18 \%)$ raphe nuclei and in the locus ceruleus $(-20 \%)$.

\section{DISCUSSION}

The results of the present metabolic mapping study demonstrate that the acute intravenous administration of a moderate dose of cocaine $(1.0 \mathrm{mg} / \mathrm{kg})$ to cocaine-naive cynomolgus monkeys produced a highly discrete pattern of decreases in cerebral metabolism restricted to specific components of the limbic system. These changes in functional activity, measured with the quantitative autoradiographic $2-\left[{ }^{14} \mathrm{C}\right] \mathrm{DG}$ method, were most robust within the ventral striatum and within a subset of the limbic areas that project to it. The affected regions include the nucleus accumbens (core and shell), portions of the hippocampal formation, entorhinal cortex, orbitofrontal cortex, and anterior portions of the cingulate cortex. This array of affected structures suggests that corticostriatal activity, originating in limbic cortex and projecting to ventral striatum, plays an important role in the acute actions of cocaine in primates. In contrast to the intense changes in functional activity evident within the limbic system, cocaine administration at this dose had few effects on cerebral metabolism within cortical and subcortical sensory and motor systems.

\section{Topography}

The pattern of metabolic alterations observed in the present study is particularly noteworthy because the cortical regions in which metabolism was altered by cocaine form a subset of those forebrain domains sending projections to the nucleus accumbens. This is shown schematically in Figure 3, in which the inputs to the nucleus accumbens and surrounding ventral striatum, as demonstrated by anatomical tracing techniques, are compared with the changes in cerebral metabolism observed in the present study. Because changes in glucose utilization in a specific brain region are thought to be attributable primarily to changes in the afferent inputs to that region (Schwartz et al., 1979; Kadekaro et al., 1985; Sokoloff, 1985), the striking overlap reported here between the territories projecting to the ventral striatum and the location of the metabolic changes in the cerebral cortex suggests that the projections arising in the orbitofrontal cortex, anterior cingulate cortex, and the hippocampal formation are responsible, at least in part, for the significant changes in glucose utilization in the ventral striatum. This overlap also may reflect a potential neural substrate by which the reinforcing effects of cocaine are mediated, in part, by limbic cortical structures.

All of the cortical sites that displayed decreased glucose utilization project to the nucleus accumbens, but not all regions that project to the nucleus accumbens exhibited a metabolic effect. In particular, the amygdaloid complex, which provides dense input to the nucleus accumbens (Russchen et al., 1985; Amaral et al., 1992), showed no detectable changes in glucose metabolism. The lack of an cffcct in the amygdala was uncxpected from an anatomical perspective and because of its reported involvement in motivated behaviors (Weiskrantz, 1956; Robbins et al., 1989; Aggleton, 1992; Gaffan, 1992). Neurons within the amygdala of the monkey, for example, increase their firing rates in the presence of stimuli once those stimuli have been paired with positive reinforcers (Nishijo et al., 1988). The failure of acute cocaine to alter functional activity in the amygdala, therefore, may be attributable in part to the lack of any conditioned context of drug administration in the present study. In self-administration paradigms or after the motivational significance of cocaine has become established after conditioning, the involvement of the amygdala may be revealed.

The primate nucleus accumbens, like that of the rodent, may be subdivided into the core and the shell based on afferent and efferent projections (Haber et al., 1990; Berendse et al., 1992; Friedman et al., 1992; Zahm and Brog, 1992; Meredith et al., 1993), as well as on the distribution of calbindin binding (Friedman et al., 1992; Meredith et al., 1993). Recent evidence in the rodent suggests that in certain contexts cocaine treatment has preferential effects in shell compared with the core of the nucleus accumbens (Pulvirenti et al., 1994; Pontieri et al., 1994), but this distinction was not apparent in the present study. Cocaine induced equivalent decreases in metabolism 


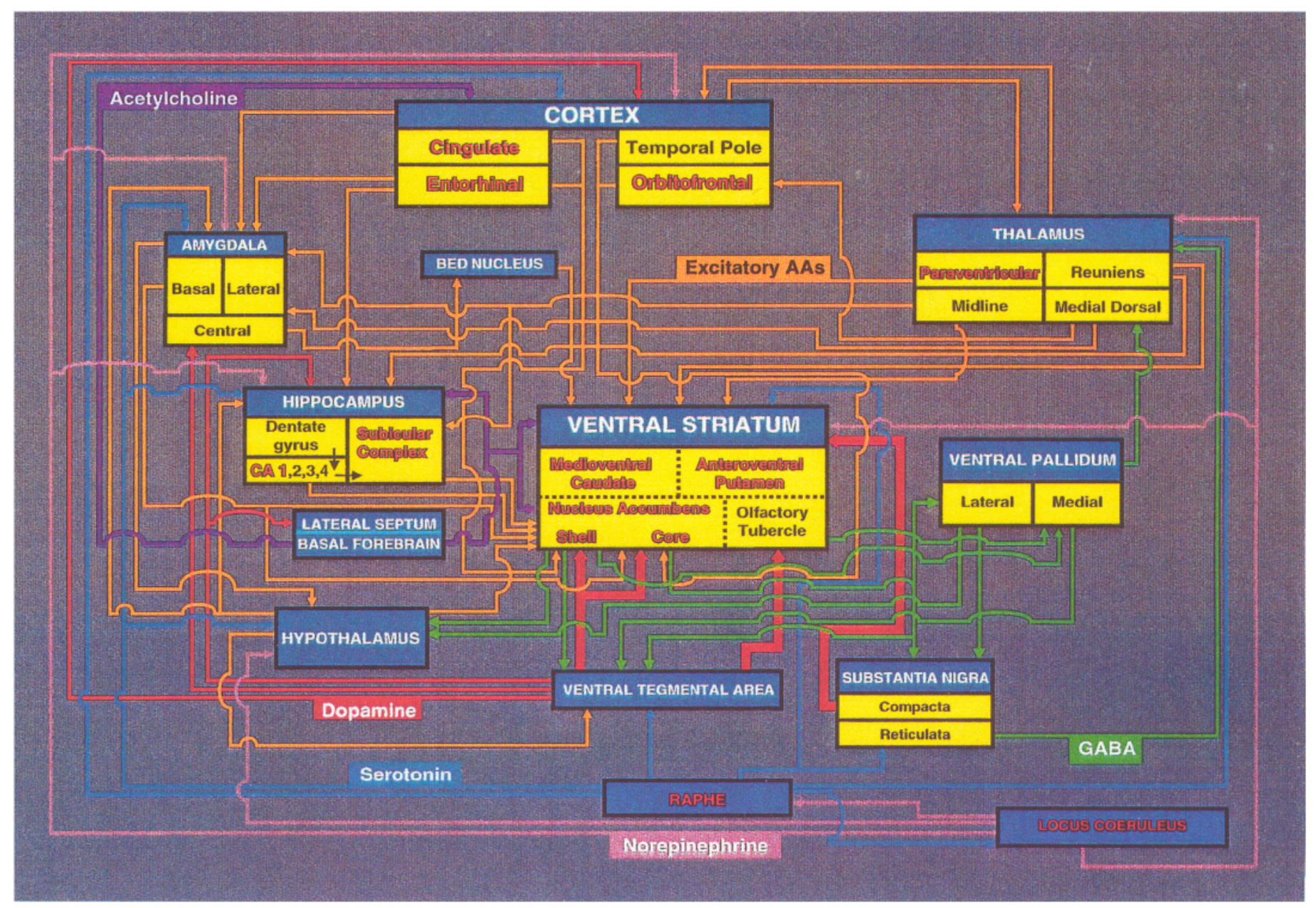

Figure 3. Schematic diagram of the connections of ventral striatum within the limbic system. Areas in which glucose utilization was altered by the administration of an acute dose of cocaine $(1.0 \mathrm{mg} / \mathrm{kg}$ ) are indicated in red, and they include portions of the ventral striatum, cortex, hippocampus, thalamus, the raphe, and the locus ceruleus. Note that cocaine produced discrete changes in functional activity within a subset of cortical and subcortical regions that project to the ventral striatum.

in both the shell and the core of the monkey. Moreover, functional activity in the cortical inputs specific to these subdivisions was not differentially altered.

Although the function of the caudate and putamen is considered to be primarily sensorimotor or cognitive in nature, the cortical inputs to portions of the anterior caudate and putamen suggest a role more characteristic of limbic function. This idea is supported by the decreased metabolism caused by cocaine administration observed in the present study. In addition, neurons contained within these striatal regions increase their firing rates in response to the presentation of rewarding stimuli or stimuli that predict the presentation of reward (Apicella et al., 1991; Schultz et al., 1992). This further supports the limbic nature of these regions and their involvement in the processing of rewardrelevant information.

\section{Role of limbic cortex}

Based largely on data generated in the rodent, the mesolimbic dopamine system, particularly the pathway from the ventral tegmental area to the nucleus accumbens, has been widely recognized as a critical substrate for the reinforcing and activating properties of cocaine and other drugs of abuse (Wise, 1978; Koob and Goeders, 1989; Kuhar et al., 1991). The present data confirm the role of the nucleus accumbens in subserving the effects of cocaine. Although electrophysiological studies in primates have shown that the neurons of the ventral striatum are sensitive to reward presentation (Apicella et al., 1991; Schultz et al., 1992), few studies have addressed the role of the nucleus accumbens in drug action in monkeys. The present data serve to extend the importance of this nucleus to the primate in the action of cocaine.

There are a number of lines of evidence showing that the orbitofrontal cortex is intimately involved in the mediation of positive reinforcement in primates (Rolls and Baylis, 1994). It has been shown, for example, that neurons in this region respond best to the presentation of rewarding stimuli, such as food and water, and shift their responsiveness depending on the motivational state of the organism (Rolls et al., 1980). Furthermore, the orbitofrontal cortex supports electrical self-stimulation in primates (Mora and Myers, 1977; Phillips et al., 1979), and orbitofrontal neurons increase their firing rates during rewarding electrical stimulation to other brain regions (Mora et al., 1980; Rolls et al., 1980). Lesions of this cortical region also have been shown to reduce the ability of monkeys to ascribe positive reinforcing value to stimuli (Baylis and Gaffan, 1991). Finally, the significance of orbitofrontal cortex to cocaine abuse is underscored further by PET studies of abstinent cocaine addicts in whom depressed rates of glucose metabolism in the orbitofrontal cortex were shown to persist for 
up to 3 months of withdrawal, an effect positivcly corrclatcd with changes in $\mathrm{D}_{2}$-receptor availability in this region (Volkow et al., 1993). Thus, the changes in functional activity within the orbitofrontal cortex and adjacent cortical areas that accompany acute cocaine administration are clearly consistent with a role for these areas as potential substrates for the modification and modulation of the central representation of reward in the monkey.

\section{Relationship of metabolic changes to the distribution of cocaine-binding sites}

Although cocaine equipotently inhibits the transport of dopamine, serotonin, and norepinephrine (Koe, 1976; Ritz et al., 1990), the behavioral effects of cocaine have been attributed chiefly to its actions at the dopamine transporter (DeWit and Wise, 1977; Colpaert et al., 1978; Miczek and Yoshimura, 1982; Ritz et al., 1987). The relationship of cocaine to dopamine synapses is emphasized by numerous binding studies using radiolabeled cocaine or labeled cocaine analogs that have shown that the greatest levels of binding are found within the dopamine-rich regions of the striatum. In postmortem human tissue, the highest density of $\left[{ }^{3} \mathrm{H}\right]$ cocaine binding was observed in caudate and putamen (Biegon et al., 1992, 1995). Infusions of [ ' $\mathrm{C}$ ]cocaine in vivo reveal a similar distribution in basal ganglia to that observed autoradiographically (Fowler et al., 1989, 1995). The binding of high-affinity tropane analogs such as $\left[{ }^{3} \mathrm{H}\right] \mathrm{WIN}-$ 35,428 (CFT) and [ ${ }^{123}$ I]RTI-55, which have high affinity for the DA transporter, also has been shown to be densest in caudate and putamen. The ventral midbrain, nucleus accumbens, and olfactory tubercle contain fewer of these binding sites, and amygdala, hippocampus, and cerebral cortex contain fewer still (Kaufman et al., 1991; Madras and Kaufman, 1994). Although cocaine has been shown to bind to other amine transporters, the regional densities of cocaine-binding sites closely parallel the regional densities of the dopamine transporter and include many of the structures in which decreases in metabolic activity were identified in the present study.

In studies by Madras and Kaufman (1994), the intravenous infusion of both behaviorally active $(0.1$ and $0.3 \mathrm{mg} / \mathrm{kg})$ and tracer doses $(0.001 \mathrm{mg} / \mathrm{kg})$ of radiolabeled cocaine to anesthetized squirrel monkeys also identified a set of structures known to contain high concentrations of the dopamine transporter. Of more importance, levels of cocaine binding were found to be highly correlated $\left(r_{x y}=0.90\right)$ with changes in rates of glucose utilization in rats receiving a behaviorally activating dose of cocaine. This strong correlation was interpreted by these authors to suggest that the functional changes associated with acute cocaine exposure are caused directly by the actions of cocaine at its binding sites on the dopamine transporter.

Although metabolic changes in the present study were evident in many of the regions in which high levels of cocaine binding have been found, the structures in which the largest decreases in functional activity were observed did not correspond to the regions with the highest densities of cocaine-binding sites. Specifically, the densest accumulation of labeled cocaine is observed in the dorsal striatum, but the largest changes in cerebral glucose metabolism were found instead in the ventral striatum, particularly the nucleus accumbens. Other regions, such as the orbitofrontal cortex and hippocampal formation, which have far fewer cocaine-binding sites than the dorsal striatum, had equivalent or greater changes in glucose utilization. Finally, some structures, particularly the substantia nigra compacta and the amygdaloid complex, which clearly have dopamine transporters, had no changes in metabolism in response to cocaine exposure. Although methodological differences exist between the study of cocaine- binding sites described above and the present study in terms of dose, time, and species of primate, it remains clear that the relative density of cocaine-hinding sites in monkey brain is not sufficient to predict the intensity of the metabolic response to cocaine. Our results are consistent with the hypothesis that the disparities between the magnitude of the functional response to cocaine administration reported here and the density of cocainebinding sites are more likely to be due to differences in the distributions of receptor subtypes expressed by the target neurons than to differences in the distribution of amine transporters to which cocaine binds.

\section{Relationship to metabolic mapping studies in the rat}

A number of clear similarities between the metabolic response to acute cocaine administration in rat and monkey are important to note. In particular, the ventral striatum is profoundly affected in both monkcys and rats (Porrino ct al., 1988; Porrino, 1993). Furthermore, in both monkey and rat, cocaine appeared to have a more profound effect on metabolism in the ventral striatum than in the dorsal striatum. This difference in the magnitude of metabolic responses between dorsal and ventral striatum may reflect a greater sensitivity of the ventral striatum to stimulants across species (Porrino and Lucignani, 1987; Porrino et al., 1988; Porrino et al., 1995).

Despite these similarities, a larger number of brain regions responded to acute cocaine administration in the monkey than in the rat (Porrino et al., 1988; Porrino, 1993). Not only is the topography of altered brain metabolism different in monkeys and rats, the directions of the metabolic responses are different as well. After the administration of cocaine, rates of cerebral glucose utilization are depressed in primates, whereas they are elevated in rodents. The source of this discrepancy is unclear, but may stem directly from differences in the structures involved and their organization. Further research clearly is needed to understand the basis of the differences in the direction of the metabolic response in primates and rodents to cocaine administration.

The present study showed that glucose metabolism is altered in a number of brain regions in the monkey, in which it is unaffected in rats, regardless of the dose of cocaine tested or the regimen of cocaine administration. In rat, metabolic effects generally have been restricted to dopaminergic circuits (Porrino et al., 1988), but in the primate, cocaine depressed metabolism in the dorsal and median raphe nuclei and the locus ceruleus, sources of forebrain serotonergic and noradrenergic innervation, respectively. These effects are consistent with the actions of cocaine at serotonin and norepinephrine transporters and with its more widespread actions in monkey compared with rat.

\section{Relationship to metabolic mapping studies in humans}

In PET and SPECT studies, the acute administration of stimulants such as cocaine or amphetamine to human subjects generally has been found to cause widespread reductions in rates of cerebral metabolism or blood flow (Mathew and Wilson, 1985; Wolkin et al., 1987; Kahn et al., 1989; London et al., 1990; Pearlson et al., 1993). Thus, both humans and nonhuman primates respond to cocaine with reductions in cerebral metabolism. The metabolic changes that follow acute cocaine administration in humans, however, were apparent throughout the entire expanse of cerebral cortex and were not restricted to limbic cortex as reported here in the monkey (Wolkin et al., 1987; London et al., 1990). It is difficult to explain why metabolic rates were unchanged in parietal and occipital cortices of monkeys, whereas in humans these posterior 
cortical regions showed decreases in metabolism as large as those found elsewhere in the human cortex (London et al., 1990). Although the reasons for these differences across species are not known, they may be due to differences in drug histories or expectations inherent in the design of human studies. Whereas the monkeys studied here had no history of drug self-administration, the human subjects studied previously had a wide range of experience with a variety of psychoactive drugs, including caffeine, nicotine, alcohol, cocaine, opiates, and psychedelics, among others. The influence of previous drug experiences and the expectations that they produce have not been investigated, but it may represent an important variable in determining the response to cocaine.

In summary, the acute intravenous administration of a moderate dose of cocaine to monkeys produces a discrete pattern of functional changes restricted to the ventral striatum and a subset of its limbic projection fields, including orbitofrontal and cingulate cortex, along with portions of the hippocampal formation. In addition, cocaine produced alterations in the metabolism of medial and dorsal raphe nuclei and the locus ceruleus. The decreased cerebral metabolism found in nonhuman primates more closely resembles data on functional activity in humans than rodents and supports the use of nonhuman primates as a model for the study of the neurobiological consequences of cocaine abuse. Furthermore, the involvement of cerebral cortex in the response to cocaine in primates suggests a means by which cocaine can influence directly the integration of the complex sensory and limbic information that is processed in these areas, not only in terms of their immediate emotional and motivational value, but in terms of their conditioned or remembered significance as well.

\section{REFERENCES}

Aggleton JP (1992) The functional effects of amygdala lesions in humans: a comparison with findings from monkeys. In: The amygdala: neurobiological aspects of emotion, memory and mental dysfunction (Aggleton JP, ed), pp 485-504. New York: Wiley.

Amaral DG, Price JL, Pitkanen A, Carmichael ST (1992) Anatomical organization of the primate amygdaloid complex. In: The amygdala: neurobiological aspects of emotion, memory and mental dysfunction (Aggleton JP, ed), pp 1-66. New York: Wiley.

Apicella P, Ljungberg T, Scarnati E, Schultz W (1991) Responses to reward in monkey dorsal and ventral striatum. Exp Brain Res $85: 491-500$.

Baylis LL, Gaffan D (1991) Amygdalectomy and ventromedial prefrontal ablation produce similar deficits in food choice and in simple object discrimination learning for an unseen reward. Exp Brain Res 86:617-622.

Berendse HW, Galis-de Graaf Y, Groenewegen HJ (1992) Topographical organization and relationship with ventral striatal compartments of prefrontal corticostriatal projections in the rat. J Comp Neurol 316:314-347.

Biegon A, Dillon K, Volkow ND, Fowler JS (1995) Quantitative autoradiographic localization and the characterization of cocaine binding sites in the human brain post-mortem. In: Sites of drug action in the human brain (Biegon A, Volkow ND, eds), pp 87-98. Ann Arbor: CRC.

Biegon A, Dillon KA, Volkow ND, Hitzemann RH, Fowler JS, Wolf AP (1992) Quantitative autoradiography of cocaine binding sites in human brain postmortcm. Synapse 10:126-130.

Colpaert FC, Niemegeers JE, Janssen PAJ (1978) Neuroleptic interference with cocaine cue: internal stimulus control of behavior and psychosis. Psychopharmacology 58:347-367.

DeWit H, Wise RA (1977) Blockade of cocaine reinforcement in rats with the dopamine blocker, pimozide, but not with the noradrenergic blockers phentolamine or phenoxybenzamine. Can J Psychol 31:195-203.

Fowler JS, Volkow ND, Wolf AP (1995) PET studies of cocaine in human brain. In: Sites of drug action in the human brain (Biegon A, Volkow ND, eds), pp 99-116. Ann Arbor: CRC.
Fowler JS, Volkow ND, Wolf AP, Dewey SL, Schlyer DJ, Macgregor RR, Hitzemann R, Logan J, Bendriem B, Gatley SJ, Christman D (1989) Mapping cocaine binding sites in human and baboon brain in vivo. Synapse 4:371-377.

Friedman DP, Porrino LJ, Vinsant S (1992) Anatomical analysis of the ventral striatum in the macaque monkey. Soc Neurosci Abstr 18:307.

Gaffan D (1992) Amygdala and the memory of reward. In: The amygdala: neurobiological aspects of emotion, memory and mental dysfunction (Aggleton JP, ed), pp 485-504. New York: Wiley.

Haber SN, Kunishio K, Mizobuchi M, Lynd-Balta E (1995) The orbital and medial prefrontal circuit through the primate basal ganglia. J Neurosci 15:4851-4867.

Haber SN, Lynd E, Kleig C, Groenewegen HJ (1990) Topographic organization of the ventral striatal efferent projections in the rhesus monkey: an anterograde tracing study. J Comp Neurol 293:282 298.

Kadekaro M, Crane AM, Sokoloff L (1985) Differential effects of electrical stimulation of sciatic nerve on metabolic activity in spinal cord and dorsal root ganglion in the rat. Proc Natl Acad Sci USA 82:6010-6013.

Kahn DA, Prohovnik I, Luca LR, Sackeim HA (1989) Dissociated effects of amphetamine on arousal and cortical blood flow in humans. Biol Psychiatry 25:755-767.

Kalivas PW, Sorg BA, Hooks MS (1993) The pharmacology and neural circuitry of sensitization to psychostimulants. Behav Pharmacol 4:315-334.

Kaufman MJ, Spealman RD, Madras BK (1991) Distribution of cocaine recognition sites in monkey brain. I. In vitro autoradiography with $\left[{ }^{3} \mathrm{H}\right]$ CFT. Synapse 9:177-187.

Kennedy C, Sakurada O, Shinohara M, Jehle M, Sokoloff L (1978) Local cerebral glucose utilization in the normal conscious Macaque monkey. J Neurochem 4:293-301.

Koe BK (1976) Molecular geometry of inhibitors of the uptake of catecholamines and serotonin in synaptosomal preparations of rat brain. $J$ Pharmacol Exp Ther 199:649-661.

Koob GF, Bloom FE (1988) Cellular and molecular mechanisms of drug dependence. Science 242:715-723.

Koob GF, Goeders NE (1989) Neuroanatomical substrates of drug selfadministration. In: The neuropharmacological basis of reward (Liebman JM, Cooper ST, eds), pp 214-263. Oxford: Clarendon.

Kuhar MJ, Ritz MC, Boja JW (1991) The dopamine hypothesis of the reinforcing properties of cocaine. Trends Neurosci 14:299-302.

London ED, Cascella NG, Wong DF, Phillips RL, Dannals RF, Links JM, Herning R, Grayson R, Jaffe JH, Wagner HN (1990) Cocaine-induced reduction of glucose utilization in human brain. Arch Gen Psychiatry 47:567-574.

London ED, Wilkerson G, Goldberg SR, Risner ME (1986) Effects of L-cocaine on local cerebral glucose utilization in the rat. Neurosci Lett 68:73-78.

Lynd-Balta E, Haber SN (1994a) The organization of midbrain projections to the ventral striatum in the primate. Neuroscience 59:609-623.

Lynd-Balta E, Haber SN (1994b) Primate striatonigral projections: a comparison of the sensorimotor-related striatum and the ventral striatum. J Comp Neurol 345:562-578.

Madras BK, Kaufman MJ (1994) Cocaine accumulates in dopamine-rich regions of primate brain after i.v. administration: comparison with mazindol distribution. Synapse 18:261-275.

Mathew RJ, Wilson WH (1985) Dextroamphetamine-induced changes in regional cerebral blood flow. Psychopharmacology 87:298-302.

Meredith GE, Pattiselanno A, Groenewegen HJ, Haber SN (1993) Shell and core in the primate ventral striatum identified with antibodies against calbindin. Soc Neurosci Abstr 19:1435.

Miczek KA, Yoshimura H (1982) Disruption of primate social behavior by $d$-amphetamine and cocaine: differential antagonism by antipsychotics. Psychopharmacology 76:163-171.

Mora F, Myers RD (1977) Brain self-stimulation: direct evidence for the involvement of dopamine in the prefrontal cortex. Science 197:1387-1389.

Mora F, Avrith DB, Rolls ET (1980) An electrophysiological and behavioural study of self-stimulation in the orbitofrontal cortex of the rhesus monkey. Brain Res Bull 5:111-115.

Nader MA, Reboussin DM (1994) The effects of behavioral history on cocaine self-administration in rhesus monkeys. Psychopharmacology $115: 53-58$

Nestler EJ, Hope BT, Widnell KL (1993) Drug addiction: a model for the molecular basis of neural plasticity. Neuron 11:995-1006. 
Nishijo H, Ono T, Nishino $H$ (1988) Single neuron responses in amygdala of alert monkey during complex sensory stimulation with affective significance. J Neurosci 8:3570-3583.

Pearlson GD, Jeffery PJ, Harris GJ, Ross CA, Fischman MW, Camargo EE (1993) Correlation of acute cocaine-induced changes in local cerebral blood flow with subjective effects. Am J Psychiatry 150:495-497.

Phillips AG, Mora F, Rolls ET (1979) Intracranial self-stimulation in orbitofrontal cortex and caudate nucleus of rhesus monkey: effects of apomorphine, pimozide, and spiroperidol. Psychopharmacology $62: 79-82$.

Pontieri FA, Colangelo V, La Riccia M, Pozzilli C, Passarelli F, Orzi F (1994) Psychostimulant drugs increase glucose utilization in the shell of the rat nucleus accumbens. NeuroReport 5:2561-2564.

Porrino LJ (1993) Functional effects of cocaine depend on route of administration. Psychopharmacology 112:343-351.

Porrino LJ, Lucignani G (1987) Different patterns of local brain energy metabolism associated with high and low doses of methylphenidate: relevance to its action in hyperactive children. Biol Psychiatry 22:126-138.

Porrino LJ, Davies HML, Childers SR (1995) Behavioral and local cerebral metabolic effects of the novel tropane analog, $2 \beta$-propanoyl-3 $\beta$-(4tolyl)-tropanc. J Pharmacol Exp Ther 272:901-910.

Porrino LJ, Domer FR, Crane AM, Sokoloff L (1988) Selective alterations in cerebral metabolism within the mesocorticolimbic dopaminergic system produced by acute cocaine administration in rats. Neuropsychopharmacology 1:109-118.

Pulvirenti L, Berrier R, Kreifeldt M, Koob GF (1994) Modulation of locomotor activity by NMDA receptors in the nucleus accumbens core and shell regions of the rat. Brain Res 664:231-236.

Ray JP, Price JL (1993) The organization of projections from the mediodorsal nucleus of the thalamus to orbital and medial prefrontal cortex in macaque monkeys. J Comp Neurol 337:1-31.

Ritz MC, Cone EJ, Kuhar MJ (1990) Cocaine inhibition of ligand binding at dopamine, norepinephrine and serotonin transporters: a structure-activity study. Life Sci 46:635-645.

Ritz MC, Lamb RJ, Goldberg SR, Kuhar MJ (1987) Cocaine receptors on dopamine transporters are related to self-administration of cocaine. Science 237:1219-1223

Robbins TW, Cador M, Taylor JR, Everitt BJ (1989) Limbic-striatal interactions in reward-related processes. Neurosci Biobehav Rev 13:155-162.

Rolls ET, Baylis LL (1994) Gustatory, olfactory, and visual convergence within the primate orbitofrontal cortex. J Neurosci 14:5437-5452.

Rolls ET, Burton MJ, Mora F (1980) Neurophysiological analysis of brain-stimulation reward in the monkey. Brain Res 194:339-357.

Russchen FT, Bakst I, Amaral DG, Price JL (1985) The amygdaloid projections in the monkey: an anterograde tracing study. Brain Res 329:241-257.
Schultz W, Apicella P, Scarnati E, Ljungberg T (1992) Neuronal activity in monkey ventral striatum related to the expectation of reward. J Neurosci 12:4595-4610.

Schwartz WJ, Smith CB, Davidsen L, Savaki HE, Sokoloff L, Mata M, Fink DJ, Gainer H (1979) Metabolic mapping of functional activity in the hypothalamo-neurohypophysial system of the rat. Science 205:723-725.

Sharkey J, McBean DE, Kelly PAT (1991) Acute cocaine administration: effects on local cerebral blood flow and metabolic demand in the rat. Brain Res 548:310-314.

Sokoloff $L$ (1985) Biochemical probes for the localization of functional activities in the central nervous system. In: Perspectives on neuroscience: from molecule to mind (Tsukada Y, ed), pp 327-364. Tokyo: Tokyo UP.

Sokoloff L, Reivich M, Kennedy C, DesRosiers MH, Patlak CS, Pettigrew KD, Sakurada O, Shinohara M (1977) The $\left[{ }^{14} \mathrm{C}\right]$ deoxyglucose method for the measurement of local cerebral glucose utilization: theory, procedure and normal values in the conscious and anesthetized albino rat. J Neurochem 28:897-916.

Szabo J, Cowan WM (1984) A stereotaxic atlas of the brain of the cynomolgus monkey (Macaca fascicularis). J Comp Neurol 222:265-300.

Volkow ND, Fowler JS, Wang G-J, Hitzemann R, Logan J, Schlyer DJ, Dewey SL, Wolf AP (1993) Decreased dopamine $D_{2}$ receptor availability is associated with reduced frontal metabolism in cocaine abusers. Synapse 14:169-177.

Volkow ND, Fowler JS, Wolf AP, Hitzemann R, Dewey SL, Bendriem B, Alpert R, Hoff A (1991) Changes in brain glucose metabolism in cocaine dependence and withdrawal. Am J Psychiatry 148:621-626.

Volkow ND, Hitzemann R, Wang G-J, Fowler JS, Wolf AP, Dewey SL, Handlesman L (1992) Long-term frontal brain metabolic changes in cocaine abusers. Synapse 11:184-190.

Weiskrantz L (1956) Behavioural changes associated with ablation of the amygdaloid complex in monkeys. J Comp Physiol Psychol 49:381-391.

Wise RA (1978) Catecholamine theories of reward: a critical review Brain Res 152:215-247.

Wolkin A, Angrist B, Wolf A, Brodie J, Wolkin B, Jaeger J, Cancro R. Rotrosen J (1987) Effects of amphetamine on local cerebral metabolism in normal and schizophrenic subjects as determined by positron emission tomography. Psychopharmacology 92:241-246.

Zahm DS, Brog JS (1992) On the significance of subterritories in the "accumbens" part of the rat ventral striatum. Neuroscience 50:751767. 